\title{
A “Guinada à direita" e a nova política externa brasileira
}

\author{
The "right turn" and the new Brazilian foreign policy
}

Tiago Nogueira Galinari

Geógrafo. Mestre em Extensão Rural. Doutor em Geografia.

Professor do Departamento de Geografia do Colégio Pedro II, Brasil

tiagogalinari@yahoo.com.br

\begin{abstract}
Resumo
O objetivo deste artigo é analisar como a política externa brasileira vem se transformando desde a "guinada à direita" do seu governo. Apesar de a direita ter retornado ao Palácio do Planalto em 2016, após o impeachment da presidente Dilma Rousseff, a "guinada à direita" da política externa brasileira se aprofundou ainda mais com a vitória de Jair Bolsonaro na corrida presidencial e, sobretudo, depois de sua posse. O contraste entre a política externa petista e a bolsonarista é enorme. Com base em informações largamente noticiadas pela imprensa, este texto identificou alguns rumos da política externa bolsonarista e discutiu como elas redefinem (e/ou redefinirão) o papel do Brasil, especialmente no que se refere à integração regional, ao arco de alianças, ao multilateralismo e aos seus esforços para se consolidar como uma liderança entre os países do Sul.
\end{abstract}

Palavras-chave: bolsonarismo; diplomacia brasileira; guinada à direita; política externa.

\begin{abstract}
The aim of this article is to analyse how the Brazilian foreign policy has been transformed since the "right turn" of the Brazilian government. Although the right returned to the "Palácio do Planalto" in 2016, after the impeachment of the President Dilma Rousseff, the "right turn" of Brazilian foreign policy intensified even more after the victory of Jair Bolsonaro in the presidential race and mainly after his inauguration. The contrast between PT's and bolsonarist's foreign policy is enormous. Based on information widely reported by the press, this text identified some directions of the bolsonarist's foreign policy and discussed how they redefine (or are going to redefine) the role of Brazil, primarily referring to the regional integration, the alliances, the multilateralism and the efforts to consolidate itself as the leader among the countries of the South.
\end{abstract}

Keywords: bolsonarism, Brazilian diplomacy, right turn, foreign policy.

\section{INTRODUÇÃO}

Nos últimos anos, o comportamento geopolítico do Brasil mudou radicalmente. O impeachment da presidente Dilma Rousseff, em 2016, deu início a consideráveis mudanças na

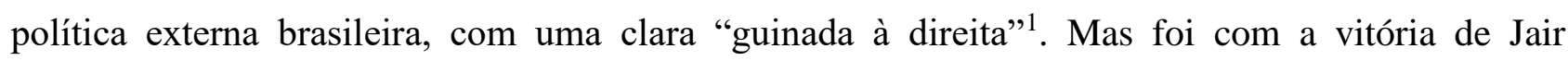

\footnotetext{
${ }^{1}$ Muitas pessoas e organizações se identificam e/ou são identificadas (pela imprensa, por adversários, por aliados, entre outros) como sendo de direita ou de esquerda. Assim, a "guinada à direita" se refere à mudança do perfil ideológico de um grupo ou, neste caso, de um governo, assumindo discursos e adotando medidas consideradas à direita do espectro político. Apesar deste texto não ter a intenção de realizar um minucioso exame conceitual sobre o tema, é importante que façamos uma pequena diferenciação entre esquerda e direita. Conforme explicado por Bobbio (2011), esquerda e direita designam contrastes antitéticos entre duas ideologias e, além de distinguir ideias, visões de mundo e programas
} 
Bolsonaro em outubro de 2018 e, sobretudo, a partir do dia 01 de janeiro de 2019, quando o novo presidente tomou posse, que a política externa brasileira assumiu, em definitivo, uma posição claramente conservadora e ainda mais à direita. Isto tem redefinido sobremaneira a posição do Brasil em relação ao mundo e tende a impactar decisivamente a Ordem Geopolítica Mundial.

O objetivo deste texto é destacar e discutir algumas das principais mudanças da política externa brasileira que se iniciaram com a "guinada à direita" do governo do país. A partir de alguns dos principais fatos envolvendo a política externa brasileira nos últimos anos foi possível identificar a mudança de rumos do Brasil nesta matéria. Ao compararmos a política externa petista com a política externa pós-impeachment, especialmente depois da ascensão de Jair Bolsonaro, demonstramos as novas posturas do país frente a algumas "questões internacionais". Para tal, levantamos e analisamos informações largamente noticiadas pela imprensa nos últimos anos. Demos atenção especial aos discursos feitos por Jair Bolsonaro no segundo semestre de 2018 (período da campanha eleitoral e do governo de transição) e, sobretudo, aos pronunciamentos e às decisões tomadas por ele (e por seu ministro de relações exteriores) nos quatro primeiros meses de governo (de janeiro a abril de 2019).

Além desta introdução, o texto está estruturado em duas partes e uma conclusão. A primeira parte realiza uma breve revisão das transformações que a política externa brasileira sofreu da ditadura militar até o final da "era petista", destacando algumas das principais características da política externa inaugurada no governo Lula. A segunda parte discute as transformações da política externa brasileira a partir desta "guinada à direita", destacando as principais frentes que vem sendo assumidas pelo Itamaraty e seus impactos geopolíticos. A conclusão sintetiza as principais diferenças entre a política externa petista e a bolsonarista, destacando os novos princípios ideológicos que regem o comportamento do governo brasileiro frente à Ordem Internacional.

\footnotetext{
políticos, estes termos também estão carregados de significado emotivo. De acordo com o autor, a principal diferença entre esquerda e direita se refere ao tratamento dado à questão do (in)igualitarismo. Assim, as doutrinas e movimentos de esquerda consideram que a maior parte das desigualdades é fruto das relações sociais e, por isso, são possíveis de serem corrigidas. Nestes parâmetros, o feminismo seria um típico movimento de esquerda, assim como outros movimentos ditos "progressistas". No plano econômico, as políticas de melhoria na distribuição de renda / riqueza e de inclusão social também poderiam ser consideradas políticas de esquerda. Já as doutrinas e movimentos de direita tendem a considerar que as pessoas são mais desiguais do que iguais e que tais desigualdades seriam naturais, por isso, incorrigíveis. Por este motivo, o pensamento de direita costuma ser mais conservador e antipático às políticas que combatam a desigualdade (como, por exemplo, cobrar mais impostos dos mais ricos para subsidiar programas de inclusão social). Por fim, é importante ponderar que "quando se atribui à esquerda uma maior sensibilidade para diminuir as desigualdades não se deseja dizer que ela pretende eliminar todas as desigualdades ou que a direita pretende conservá-las todas, mas no máximo que a primeira é mais igualitária e que a segunda é mais inigualitária" (BOBBIO, 2011, p.119).
} 


\section{O PAPEL DESEMPENHADO PELO BRASIL NA ORDEM INTERNACIONAL: DA DITADURA MILITAR À "ERA PETISTA"}

Ainda durante a ditadura militar (1964-1985), "o Brasil mudou a sua posição na economia-mundo, assumindo a categoria de semiperiferia como uma potência regional" (BECKER e EGLER, 2010, p.123). E, mais recentemente, especialmente durante o governo Lula (2003-2010), o Brasil assumiu o importante papel de líder entre os países do Sul.

O papel ocupado pelo Brasil na divisão internacional do trabalho, assim como a sua posição na ordem geopolítica mundial, é fruto de escolhas políticas do passado (e do presente). Evidentemente, as escolhas feitas pelos governantes resultam dos diferentes contextos históricogeográficos e da influência que diferentes grupos exercem na máquina estatal.

Da década de 1920 até os anos de 1980, o pensamento geopolítico brasileiro esteve restrito, quase exclusivamente, aos meios militares. Com isso, a geopolítica instrumental produzida nos círculos militares (especialmente no exército), baseada em conceitos e práticas da geopolítica clássica (ratzeliana e mackinderiana), repercutiu consideravelmente nas políticas (internas e externas) do Estado brasileiro (COSTA; THÉRY, 2016).

O pensamento geopolítico dos militares se convergia na ideia de que o Brasil precisava de uma ocupação efetiva de seu território e de que "o Brasil deve, por todos os meios à sua disposição, procurar expandir sua influência sobre os países vizinhos da América do Sul" (COSTA; THÉRY, 2016, p.5). Em outras palavras, não se tratava de integrar o continente, mas de submetê-lo aos interesses do Brasil numa relação de subalternização. Durante a ditadura militar, por óbvio, os militares tiveram o protagonismo na condução da política externa brasileira e, durante este período, este pensamento dificultou alianças e projetos de integração regional na América do Sul.

Todavia, não foi somente o Brasil que experimentou uma ditadura militar durante este período. A década de 1970 foi marcada por ditaduras militares em grande parte da América do Sul e, mesmo com as dificuldades de estabelecer projetos regionais durante este período, houve significativa cooperação e interação entre os aparelhos repressivos criados pelos governos autoritários do Cone Sul. Apesar disso, nunca existiu, de fato, uma integração oficial dos sistemas de repressão destas ditaduras (PENNA FILHO, 2009).

Uma das principais marcas da política externa brasileira durante a primeira década da ditadura militar foi o alinhamento automático aos EUA. A Doutrina de Segurança Nacional deu o suporte teórico-conceitual necessário para que, no contexto da guerra fria, a política externa do país pendesse para lado dos estadunidenses. Além do discurso anticomunista, o Brasil realizou uma ofensiva diplomática na América Latina, através de relacionamentos bilaterais que refletiam o interesse dos EUA e do Brasil na região. Assim, ao mesmo tempo em que fortalecia laços diplomáticos com outros países alinhados aos EUA, o Brasil também deu apoio logístico secreto 
para o sucesso de golpes militares em países vizinhos, como foi o caso da Bolívia. Concomitantemente, o Brasil também procurou aumentar a sua influência econômica na região e neutralizar a Argentina, de modo a garantir a sua posição de potência regional (BECKER; EGLER, 2010).

Contudo, este quadro começou a mudar ainda no governo Geisel (1974-1979). A política de defesa brasileira, assim como a de seus vizinhos, paulatinamente perdeu o caráter exclusivamente militar e passou a valorizar a diplomacia e a reconsiderar a importância de uma estratégia que privilegiasse a integração. As relações relativamente hostis entre os regimes militares nos países sul-americanos - lembremo-nos das pretensões bélico-nucleares de Brasil e Argentina foram pouco a pouco substituídas por uma diplomacia baseada em confiança e diálogo. Com base na ideia de "pragmatismo responsável", ou seja, no entendimento de que os interesses econômicos sobrepõem-se aos ideológicos, o Brasil estabeleceu alguns acordos internacionais que contrariavam os interesses norte-americanos, como foi o caso do tratado nuclear com a Alemanha, em 1975. Além disso, o Brasil aumentou a sua interação com outros países do Sul, inclusive com alguns "socialistas", como ocorreu ao reatar os laços diplomáticos com a China, em 1974. Foi a partir do governo Geisel, também, que o Brasil aumentou a sua presença no Oriente Médio, o que foi motivado, entre outras coisas, pela primeira crise do petróleo (1973). Deste modo, a despeito das boas relações com Israel, o Brasil se aproximou mais dos países árabes, a fim de garantir o abastecimento de petróleo (BECKER; EGLER, 2010).

A década de 1980 marcou o esgotamento do governo autoritário no Brasil, o que impactou o pensamento geopolítico no país. Como nos conta Costa e Théry (2016), a partir desta década, a geopolítica brasileira se "civilizou", pois, na medida em que chegou ao ambiente universitário e intelectual, a geopolítica passou a ser pensada e exercitada também (ou principalmente) por civis. Isto repercutiu drasticamente nas políticas de defesa e de integração regional. O novo quadro institucional e intelectual provocou uma considerável mudança de paradigmas.

Com isso, os EUA perderam ainda mais influência na América do Sul. A rejeição dos países sul-americanos ao projeto estadunidense da ALCA (Área de Livre Comércio das Américas), a partir de forte influência brasileira e argentina, é um demonstrativo das mudanças de rumos na América do Sul e das intenções do Brasil neste continente. A criação do Mercosul (Mercado Comum do Sul), em 1991, reforçou os compromissos brasileiros para a integração regional. A entrada da Venezuela, em 2012, a partir de forte apoio brasileiro, "fez com que o Mercosul articulasse, pela primeira vez, o continente, dos países do Prata aos da Bacia Amazônica" (COSTA; THÉRY, p.9).

O Brasil se consolidou como uma liderança diplomática na América do Sul, se colocando como um mediador para contornar problemas e litígios no continente. As hostilidades entre os 
“países amazônicos", como é o caso das tensões entre Venezuela e Colômbia, ou das disputas entre Peru e Equador, tiveram o Brasil como importante conciliador. Além disso, os tratados sobre a Amazônia foram significativamente ampliados. É o caso do Tratado de Cooperação Amazônica (criado em 1978), que foi aprofundado nas décadas de 1990 e 2000, dando origem à OTCA (Organização do Tratado de Cooperação Amazônica). Sediada em Brasília, a organização é um importante mecanismo estratégico de cooperação entre os países da região amazônica.

De acordo com Costa (2009), os acordos de cooperação do Mercosul tenderam a "transbordar" para o restante do subcontinente. Desde a criação deste bloco, os tratados multilaterais se multiplicaram e foram reforçados. O lançamento do IIRSA (Iniciativa para a Integração da Infraestrutura Regional Sul-Americana), em 2000, além da criação da Unasul (União das Nações Sul-Americanas) e do Conselho de Defesa Sul-americana, ambos em 2008, selaram as intenções de promover uma integração que abrangesse praticamente toda a América do Sul. A liderança brasileira neste processo é notória, tendo sido um dos principais responsáveis pela articulação política e diplomática, mediação de conflitos e estímulo à integração. Ao invés de “absorver" os demais países, como era pensado pelos geopolíticos militares, o raciocínio geopolítico que dirigiu a política e a diplomacia brasileira pós-redemocratização, com destaque para os governos petistas, passou a enxergar o Brasil como o líder de um grande projeto de integração regional e de construção de uma Ordem efetivamente multipolar.

Deste modo, apesar de as iniciativas para integração regional ter aumentado na década de 1990, foi no curso deste terceiro milênio que tal integração se efetivou. A crise do neoliberalismo implantado na América do Sul no final do século XX (com o aumento das desigualdades, pobreza e desemprego) contribuiu para que no início do terceiro milênio houvesse uma "virada à esquerda" no continente. "Neste panorama latino-americano, pontilhado por governos de esquerda, criaram-se condições para avanços nos projetos e processos de integração regional" (CARVALHO; GUERRA, 2016, p.270).

No caso do Brasil, a chegada da esquerda ao poder aconteceu com a vitória petista nas eleições de 2002. No início do governo Lula, algumas diferenças em relação ao governo se seu antecessor, Fernando Henrique Cardoso (1995-2002), já podiam ser notadas. Conforme destacado por Almeida (2004), o início do governo Lula se esforçou mais para ocupar uma cadeira permanente no Conselho de Segurança da ONU e teve uma retórica mais incisiva em defesa do multilateralismo que o seu antecessor. Além disso, ao invés de se dedicar apenas ao diálogo, a nova política externa procurou estabelecer uma coordenação entre os países do Sul através de um grande arco de alianças, o que reforçou as relações Sul-Sul.

Ao longo das administrações petistas, notamos que, para além da integração regional, o país também empreendeu grandes esforços para se consolidar como um importante player nas 
relações internacionais. A presença militar no Haiti (2004-2017) e a tentativa de modernizar suas forças armadas - a partir da construção do submarino nuclear e da compra dos caças suecos Gripen, por exemplo - procuraram, entre outras coisas, justificar a presença do Brasil neste organismo. Já o empenho para a consolidação do BRICS - grupo formado por Brasil, Rússia, Índia, China e África do Sul - demonstra o interesse em estabelecer uma Ordem Geopolítica Mundial com uma feição mais multipolar. Como resultado de todos estes esforços, o país passou a ser visto como uma importante liderança do Sul, defendendo pautas importantes para grande parte dos países em desenvolvimento em rodadas da OMC (Organização Mundial do Comércio), em reuniões do G20 e em outros fóruns internacionais.

Como uma liderança dos países do Sul, o Itamaraty se posicionou em defesa dos interesses dos países em desenvolvimento. Em 2010, por exemplo, ao manifestar publicamente sua preocupação com a aprovação de uma legislação imigratória mais restritiva no Arizona (EUA), o Itamaraty se posicionou a favor de uma política imigratória mais flexível e abrangente, algo interessante não somente para o Brasil, mas também para a maior parte dos países do $\mathrm{Sul}^{2}$. Evidentemente, este posicionamento colidiu com os interesses estadunidenses sobre a matéria.

A política externa "ativa e altiva" do governo Lula, conforme sempre repetido por seu chanceler, Celso Amorim, se diferenciou em vários pontos da política externa de seu antecessor. Entretanto, de acordo com Almeida (2004), a nova política externa estava mais na linha da "continuidade" do que na de "ruptura" em relação ao que já estava em curso. Assim, apesar de os governos petistas terem dado mais importância para a integração regional e terem aprofundado algumas alianças, o Itamaraty não rompeu com a tradição da política externa brasileira iniciada após a redemocratização, tampouco mudou os rumos dela.

É importante destacar que o governo Dilma (2011-2016), apesar de seu caráter menos "ativo e altivo" em matéria de política externa, não mudou os rumos da política externa inaugurada ainda durante o governo Lula. Uma das marcas dos governos petistas nesta matéria foi permitir que somente diplomatas de carreira ocupassem o posto de chanceler. Isto contribuiu para a eficiência da política externa e garantiu a permanência de uma chancelaria pragmática e profissional.

Os princípios ideológicos do PT (Partido dos Trabalhadores) se combinaram com as políticas que já estavam em curso desde a redemocratização, o que fez com que a "virada à esquerda" fosse relativamente suave em matéria de política externa. Embora seja evidente que o estreitamento das relações diplomáticas com alguns países seja, entre outros fatores, resultado de uma afinidade ideológica, como ocorreu com Cuba, Venezuela e Bolívia, também é evidente o pragmatismo da política externa petista. Semelhante ao governo Geisel, a política externa do

\footnotetext{
${ }^{2}$ Itamaraty manifesta preocupação sobre Lei anti-imigratória do Arizona. Ministério de relações exteriores. Publicado em 03 de maio de 2010. Disponível em: http://www.brasileirosnomundo.itamaraty.gov.br/noticias/itamaratymanifesta-preocupacao-sobre-a-lei-anti-imigratoria-do-arizona/?searchterm=estrangeiros\%20no\%20Brasil.
} 
ministro Celso Amorim procurou estabelecer relações comerciais com uma gama de países que ofereciam vantagens econômicas para o Brasil.

Além disso, o Brasil se esforçou para desempenhar o papel de mediador de conflitos na América do Sul. Na crise fronteiriça entre Venezuela e Colômbia ocorrida em 2010, por exemplo, o governo Lula procurou uma negociação conjunta com seu aliado venezuelano, Hugo Chaves, e com o governo colombiano de direita, presidido por Álvaro Uribe ${ }^{3}$. Aliás, em função do pragmatismo de sua política externa, o governo Lula manteve boas relações tanto com governos de esquerda como com governos de direita. Vale lembrar que a "virada à esquerda" petista também foi significativamente branda no que se refere às políticas domésticas, tendo em vista que as administrações petistas mantiveram grande parte das políticas econômicas de seus antecessores.

No que se refere às iniciativas de integração regional, o protagonismo do Brasil se manifestou tanto através da via diplomática como através do financiamento dos grandes projetos do IIRSA. O BNDES (Banco Nacional de Desenvolvimento Econômico e Social) se tornou um dos principais financiadores destes projetos e a atuação de empresas estatais (com destaque para a Petrobrás) e privadas (especialmente do ramo da construção civil) deram suporte para a integração econômica da América do Sul no início do terceiro milênio (COSTA, 2009).

Até 2014, o governo federal brasileiro havia subsidiado maciçamente a atuação de empresas brasileiras em projetos de infraestrutura nos países vizinhos. No entanto, a crise econômica e os escândalos de corrupção revelados pela Operação Lava Jato interromperam muitos destes investimentos.

Algumas opiniões divergem sobre as motivações geopolíticas e o papel desempenhado pelo Brasil no processo de integração da América do Sul. Afinal, os investimentos realizados pelo Brasil seriam parte da estratégia brasileira para fortalecer os laços econômicos e políticos dos países sul-americanos ou uma tentativa de exercer sua hegemonia no continente?

Para Zibechi (2012), as iniciativas de integração regional encabeçadas pelo Brasil se desdobraram de um projeto muito mais ambicioso e menos diplomático do que aquele anunciado pelos governos petistas, pois a nova política externa brasileira teria um caráter subimperialista, ou, quiçá, imperialista. De fato, a expansão econômica brasileira neste terceiro milênio ocupou espaços na América do Sul que antes eram hegemonizados pelos EUA. Deste modo, nas últimas décadas, alguns países sul-americanos passaram a se subordinar mais e mais aos ditames da diplomacia e das empresas brasileiras. A América do Sul e a África ocidental estariam, nesta perspectiva, se convertendo em regiões de interesse do crescente "capital brasileiro". Como consequência deste expansionismo:

\footnotetext{
3 'Brasil está empenhado em diálogo entre Chávez e Colômbia', diz assessor de Lula. Reportagem de Fabrícia Peixoto e Claudia Jardim. BBC Brasil. Publicado em 22 de julho de 2010. Disponível em: https://www.bbc.com/portuguese/noticias/2010/07/100722_reax_venezuela_cj_cq.shtml.
} 
Em alguns países pequenos, o Brasil controla a economia, o sistema bancário, parte do Estado mediante os impostos que pagam suas empresas e mesmo alguns movimentos sociais por meio do financiamento de fóruns sociais que nunca discutem o expansionismo brasileiro (ZIBECHI, 2012, p.22).

Quanto a isso, Albuquerque (2011) chama a atenção para a necessidade de o Brasil não repetir as relações de centro-periferia que marcaram as relações dos EUA com a América Latina e, de certa maneira, também passaram a marcar, mais recentemente, as relações da China com esta região. O Brasil precisaria, neste sentido, se esforçar para o desenvolvimento de seus vizinhos. Desta forma, "os países vizinhos também devem se industrializar e, para tanto, necessitam acessar o mercado brasileiro de forma privilegiada, caso contrário a integração regional continuará como uma mão de via única em favor das empresas brasileiras. (ALBUQUERQUE, 2011, p.235).

Ao contrário da maioria das iniciativas de integração regional ao redor do mundo, a ambição maior dos países sul-americanos que vêm se engajando nos projetos de integração regional é, de acordo com Costa $(2009$, p.4), “conjugar o máximo de integração econômica a uma macroconcertação político-institucional de natureza transnacional", neste sentido, "a integração sulamericana tende a reproduzir aqui o percurso seguido até o presente pela União Européia".

Contudo, existem alguns obstáculos que precisam ser superados e, para tal, o Brasil teria um papel importantíssimo. Entre os especialistas, há o consenso de que o "fator de risco mais importante para o futuro da integração é o aprofundamento das assimetrias graves entre os países da região" (COSTA; THÉRY, 2016, p.11). Isto vem obrigando a adoção de medidas de promoção de maior equidade no desenvolvimento regional, a fim de superar os problemas relativos à desproporção das economias (semelhante ao que é feito no âmbito da União Europeia). Para o Brasil, então, seria necessário ceder a algumas reivindicações dos vizinhos e apoiar políticas compensatórias, como os "fundos estruturais", mesmo que elas não sejam, a primeira vista, vantajosas para o país.

Nas últimas décadas, especialmente neste terceiro milênio, a importância brasileira no âmbito internacional também aumentou em razão de seu potencial energético. O crescimento da produção de petróleo (em razão da descoberta do pré-sal e do aumento da capacidade produtiva da Petrobrás) diminuiu a necessidade de importação deste recurso. Aliado a isso, os investimentos na produção de biocombustíveis, a ampliação da produção de energia hidrelétrica e o potencial de utilização de fontes alternativas aumentou a importância do Brasil no cenário geopolítico e energético internacional (PEREIRA, 2010).

O governo federal também passou incentivar, a partir dos governos petistas, a produção e uso de biodiesel, além de investir em tecnologias para este setor. Explorando as suas condições internas "favoráveis", tais como "disponibilidades de terras, água, capitais e mão de obra, que dão 
ao país grandes vantagens em relação aos demais países do mundo em matéria de agroenergia”, o Brasil procurou explorar novas matrizes energéticas e se consolidar como o principal produtor e exportador global de bioenergia (BARROS; STEINBERGER, 2014, p.422). O objetivo era, claramente, transformar o Brasil numa "potência agroenergética".

Contudo, a tentativa de transformar o Brasil numa "potência agroenergética" contribui para a consolidação do caráter agroexportador do país, ao invés de induzir a sua (re)industrialização. Como resultado, os laços econômicos entre Brasil e China se reforçaram e o Brasil e tornou num dos principais fornecedores de produtos primários para a China.

Conforme destacado por Brandão (2017), o boom das commodities que resultou do aumento da demanda chinesa contribuiu para uma profunda "especialização regressiva" do Brasil, pois aprofundou a "vocação" do país para a exploração dos recursos minerais e agrícolas, o que reforçou a submissão brasileira aos centros hegemônicos mundiais.

Como uma das mais importantes transformações geopolíticas na América do Sul neste terceiro milênio, a China vem, paulatinamente, substituindo os EUA como principal "potência parceira". A aproximação política da China com o Brasil foi reforçada pelo BRICS e o vínculo comercial entre a China e a América do Sul vem se consolidando graças à grande demanda chinesa por commodities. Contudo, pensar nesta aproximação da América do Sul com a China como um exemplo de consolidação das relações Sul-Sul é se esquecer "que a China põe em prática uma relação centro-periferia ainda mais brutal aos interesses regionais de longo prazo" (ALBUQUERQUE, 2011, p.234).

A China também passou a ocupar espaços que eram hegemonizados pelo Brasil na América do Sul. No Equador, por exemplo, escândalos e demais problemas envolvendo empresas brasileiras (Odebrecht, Petrobrás etc.) contribuíram para que o "capital brasileiro" se retirasse deste país, facilitando a entrada ostensiva de investimentos chineses (ZIBECHI, 2012).

Carvalho e Guerra (2016) chamam a atenção para o caráter selvagem do capitalismo chinês neste início de século XXI, designando a relação desta potência com outros países de "novo imperialismo chinês". Além disso, a forte dependência do Brasil e de seus vizinhos em relação à China já mostrou que não é sustentável, pois bastou a potência asiática diminuir a demanda por produtos primários para a economia brasileira e de outros países colapsarem. Para as autoras, esta é, inclusive, uma das razões para a "guinada à direita" que a América do Sul vem experimentando.

De uma maneira geral, as crises econômicas experimentadas em alguns países sulamericanos contribuíram para a ascensão de movimentos políticos de direita na região. No Brasil e na Argentina - principais economias da região -, as crises pavimentaram o caminho para que grupos de direita chegassem à presidência da república. 
Assim, sem desconsiderar a importância dos escândalos de corrupção e a justificativa técnica dos crimes de responsabilidade fiscal, o impeachment de Dilma Rousseff é resultado direto da crise econômica que vem assolando o Brasil desde 2014. Independente dos equívocos de sua política econômica, não há como negar que a queda dos preços das commodities impactou negativamente a economia brasileira. Em resumo, a crise econômica foi uma das principais responsáveis pela crise política que assolou o segundo mandato da presidente Dilma e que culminou em seu impeachment. Seja como for, no dia 12 de maio de 2016 a então presidente foi afastada do cargo e no dia 31 de agosto deste mesmo ano ela perdeu definitivamente o seu mandato presidencial.

Como bem lembrado por Brandão (2017), a cada crise do sistema político brasileiro, ideias conservadoras (algumas reacionárias) se multiplicam sob a alegação de "passar o país a limpo". Na década de 1990, tais ideias apenas advogavam a redução do tamanho (e das funções) do Estado e uma ampliação das privatizações. Nos últimos anos, a narrativa liberal-conservadora retornou com muitíssima intensidade e, com a vitória de Jair Bolsonaro, o conservadorismo ganhou um novo patamar. Tal virada ideológica vem impactando severamente as políticas interna e externa do país.

\section{A "GUINADA À DIREITA" E AS NOVAS AMARRAS IDEOLÓGICAS}

As posições do governo Temer (2016-2018) se contrastaram sobremaneira com os posicionamentos dos governos petistas em diferentes matérias, incluindo na política externa. Desde que Temer assumiu o poder (primeiro interinamente e depois de forma permanente), as relações exteriores do Brasil se inclinaram para a direita do espectro político.

Apesar de não se tratar de uma política de direita (ou de esquerda), vale mencionar uma preocupante mudança ocorrida no ministério das relações exteriores. Ao contrário do que ocorreu ao longo da "era petista", durante a gestão Temer o cargo mais alto deste ministério não foi ocupado por diplomatas de carreira, mas por políticos de sua base aliada - primeiro pelo senador José Serra e depois pelo senador Aloysio Nunes, ambos do PSDB. O governo Temer também criou cargos temporários que permitiram que estes ministros tivessem em seus gabinetes assessores de fora do Itamaraty.

Um decreto assinado no início do governo Bolsonaro ${ }^{4}$ passou a autorizar essa prática em caráter permanente, além de prever, também, a possibilidade de diplomatas em nível inferior na carreira ocuparem funções até então desempenhadas apenas por diplomatas em nível superior na

\footnotetext{
${ }^{4}$ Trata-se do Decreto $\mathrm{n}^{\circ}$ 9.683, de 9 de janeiro de 2019, assinado pelo presidente, por seu chanceler e pelo ministro da economia, Paulo Guedes.
} 
carreira $^{5}$. As medidas deste decreto, subvertendo a hierarquia tradicional do Itamaraty, facilitam o aparelhamento do ministério de relações exteriores, pois permite que os simpatizantes do governo sejam mais facilmente promovidos. Curiosamente, uma das principais críticas de Bolsonaro e de seus aliados ao governo petista se referia, justamente, ao suposto aparelhamento realizado pelo PT nos órgãos de Estado, como é o caso do Itamaraty. Ao que parece, a direita que ascendeu pósimpeachment está rompendo com a tradição meritocrática do ministério de relações exteriores submetendo-o mais aos interesses de governo do que aos de Estado -, o que configuraria num perigoso movimento de desprofissionalização do Itamaraty.

De todo modo, é importante lembrar que, diferentemente de Temer, o presidente Bolsonaro nomeou um diplomata de carreira para o cargo de chanceler. O antes desconhecido Ernesto Araújo rapidamente se notabilizou por seus posicionamentos ultraconservadores e controversos ${ }^{6}$. Seja em entrevistas ou em textos publicados (incluindo em seu blog pessoal ${ }^{7}$ ), o novo chanceler faz questão de expressar o seu desprezo pelas ideias, movimentos e pessoas de esquerda. Emanando um discurso religioso, Ernesto Araújo não esconde a sua simpatia por governos que tiveram uma “guinada à extrema-direita" nos últimos anos, como são os casos dos governos húngaro e polonês ${ }^{8}$. Dentro do governo, o novo chanceler é um dos principais defensores do estreitamento das relações com os EUA, cujo governo tem apresentado uma agenda contrária ao multilateralismo ${ }^{9}$. Não por acaso, logo na cerimônia de transferência de cargo, Araújo fez questão de dizer que "[nós] não pediremos permissão para a ordem global"10, num posicionamento claramente hostil ao multilateralismo.

O fato que mais marcou a "guinada à direita" do governo brasileiro desde o impeachment de Dilma Roussef foi o afastamento imediato do país em relação à Venezuela, cujo governo é visto como um aliado ideológico do PT. De fato, o presidente venezuelano, o chavista Nicolás Maduro, se posicionou publicamente contra o impeachment, chamando-o de golpe de Estado. Seja como for, em dezembro de 2016 e com forte apoio do governo brasileiro, a Venezuela foi suspensa do Mercosul. Apesar das argumentações técnicas (de não cumprimento dos compromissos assumidos

\footnotetext{
${ }^{5}$ Decreto permite assessores no Itamaraty sem carreira diplomática. Reportagem do Jornal Nacional. G1. Publicado em 10 de janeiro de 2019. Disponível em: https://g1.globo.com/jornal-nacional/noticia/2019/01/10/decretoque-permite-assessores-no-itamaraty-sem-carreira-diplomatica.ghtml.

${ }^{6}$ As opiniões polêmicas do novo chanceler sobre raça, fake news e 8 temas. Reportagem de João Pedro Caleiro. Exame. Publicado em 14 de novembro de 2018. Disponível em: https://exame.abril.com.br/brasil/as-opinioes-polemicas-do-novo-chanceler-sobre-raca-fake-news-e-8temas/.

7 "Metapolítica 17 - contra o globalismo". Disponível em: https://www.metapoliticabrasil.com/.

${ }^{8}$ Araújo critica globalismo na política externa brasileira. Estadão conteúdo / Istoé. Publicado em 02 de janeiro de 2019. Disponível em: https://istoe.com.br/araujo-critica-globalismo-na-politica-externa-brasileira/.

${ }^{9}$ Trump rejeita multilateralismo em discurso na ONU. Reportagem de Rafael Vazquez. Valor econômico. Publicado em 25 de setembro de 2018. Disponível em: https://www.valor.com.br/internacional/5882347/trump-rejeitamultilateralismo-em-discurso-na-onu.

${ }^{10}$ Ernesto Araújo estreia 'olavismo' no Itamaraty e dedica pouco espaço à pauta comercial. Reportagem de Ricardo Della Coletta. EL PAÍS. Publicado em 03 de janeiro de 2019. Disponível em: https://brasil.elpais.com/brasil/2019/01/02/politica/1546464944_513470.html.
} 
com o bloco ${ }^{11}$ ), a verdade é que dificilmente a Venezuela teria sido suspensa se não tivesse ocorrido esta "guinada à direita" no continente, com a eleição de Mauricio Macri na Argentina e o impedimento de Dilma Rousseff no Brasil. Assim, da mesma forma que o empenho brasileiro para a entrada da Venezuela no Mercosul, em 2012, possuía motivações ideológicas, a sua suspensão, em 2016, também estava repleta de motivações ideológicas.

No final de 2017, as relações entre Brasil e Venezuela se tornaram ainda piores. Depois de os governos destes países trocarem muitas críticas, o governo venezuelano expulsou o embaixador brasileiro e em resposta o governo brasileiro fez o mesmo ${ }^{12}$. Já em maio de 2018, os quatorze países do Grupo de Lima $^{13}$ não reconheceram a vitória de Nicolás Maduro na eleição presidencial venezuelana ${ }^{14}$, o que aumentou as tensões entre Brasil e Venezuela.

O agravamento da crise política, econômica e humanitária na Venezuela e a vitória de Jair Bolsonaro no Brasil complicaram ainda mais as relações entre os dois países. Ao ser reconduzido ao cargo em janeiro de 2019 (depois da contestada eleição de maio de 2018), parte da comunidade internacional - encabeçada pelos EUA e seguido pelo Brasil - não reconheceu a legitimidade do governo Maduro e, ainda, passou a reconhecer o presidente da assembleia nacional venezuelana, Juan Guaidó, como presidente interino da Venezuela.

Para piorar, o Brasil firmou um acordo com os EUA e com Guaidó - desconsiderando a autoridade do governo chavista - para o envio de ajuda humanitária através da fronteira BrasilVenezuela. Como resposta, o governo de Nicolás Maduro decidiu bloquear o lado venezuelano da fronteira ${ }^{15}$.

A politização e a falta de neutralidade desta ajuda humanitária foi duramente criticada pela Cruz Vermelha ${ }^{16}$. A maneira como esta ajuda estava sendo conduzida parecia servir mais para enfraquecer o governo Maduro e para legitimar Guaidó como presidente do que para mitigar a grave crise que assolava a Venezuela. Em meio a tudo isso, o governo chavista aprofundou as suas

\footnotetext{
${ }^{11}$ Serra confirma a suspensão da Venezuela do Mercosul. Reportagem de Daniel Mello. Agência Brasil / EBC. Publicado em 02 de dezembro de 2016. Disponível em: http://agenciabrasil.ebc.com.br/internacional/noticia/201612/serra-confirma-suspensao-da-venezuela-do-mercosul.

${ }^{12}$ Em resposta à Venezuela, Brasil decide expulsar principal diplomata do país. Reportagem de Eliane Oliveira. $\mathrm{O}$ Globo. Publicado em 27 de dezembro de 2017. Disponível em: https://oglobo.globo.com/mundo/em-respostavenezuela-brasil-decide-expulsar-principal-diplomata-do-pais-22229999.

${ }^{13}$ Grupo formado em 2017 para discutir a crise venezuelana. Atualmente, compõem o grupo: Argentina, Brasil, Canadá, Chile, Colômbia, Costa Rica, Guatemala, Guiana, Honduras, México, Panamá, Paraguai, Peru e Santa Lúcia.

${ }^{14}$ Brasil não reconhece vitória de Maduro; grupo de 14 países reduzirá relações com o país. Reportagem de Talita Machao. UOL. Publicado em 21 de maio de 2018. Disponível em: https://noticias.uol.com.br/internacional/ultimasnoticias/2018/05/21/brasil-nao-reconhece-vitoria-de-maduro-bloco-de-14-paises-reduzira-relacoes-com-avenezuela.htm.

${ }^{15}$ Uma semana após anúncio de ajuda à Venezuela, insumos ainda aguardam em galpão. IG / Último Segundo. Publicado em 26 de fevereiro de 2019. Disponível em: https://ultimosegundo.ig.com.br/brasil/2019-02-26/ajudahumanitaria-brasil-venezuela.html.

${ }^{16}$ As críticas da Cruz Vermelha à ajuda humanitária na Venezuela. Reportagem de João Paulo Charleaux. Nexo Jornal. Publicado em 25 de fevereiro de 2019. Disponível em: https://www.nexojornal.com.br/expresso/2019/02/25/Ascr\%C3\%ADticas-da-Cruz-Vermelha-\%C3\%A0-ajuda-humanit\%C3\%A1ria-na-Venezuela.
} 
relações econômicas e militares com a Rússia ${ }^{17}$ e o Brasil flertou com a possibilidade de ceder o seu território para operações militares dos EUA ${ }^{18}$, algo que não ocorria desde a II Guerra Mundial.

A presença militar dos EUA e da Rússia na América do Sul é, geopoliticamente, desinteressante para o Brasil. Uma atuação diplomática brasileira poderia amenizar as tensões no continente e, consequentemente, diminuir a presença de potências estrangeiras na região. Mas ao invés de procurar reverter este quadro de instabilidade e militarização da região, o Brasil endossou a interferência estadunidense na Venezuela.

Além de ameaçar a integração regional sul-americana, o comportamento do governo brasileiro frente a esta questão aumenta os riscos de conflitos armados no continente. Ao desconsiderar o histórico papel desempenhado pelo Brasil como mediador de conflitos na América do Sul, o novo presidente e seu chanceler rompem com a tradição da diplomacia conciliatória brasileira. Por tudo isso, parte das forças armadas e da ala militar presentes no governo demonstraram publicamente o incômodo com tratamento dado pelo chanceler brasileiro à "questão venezuelana"19.

A integração sul-americana, aliás, passou a sofrer alguns revezes nos últimos anos. Em abril de 2018, Argentina, Brasil, Chile e Paraguai, países cujos governos "guinaram à direita" nos últimos anos, além de Colômbia e Peru, países historicamente governados por partidos à direita do espectro político, decidiram se afastar por tempo indeterminado da Unasul ${ }^{20}$. Já o governo Bolsonaro, por sua vez, foi além e defendeu a substituição da Unasul por outro organismo multilateral sul-americano mais "flexível” e que excluiria a Venezuela ${ }^{21}$ chavista. Em abril de 2019, o governo brasileiro formalizou a retirada do Brasil da Unasul para poder integrar o Prosul (Fórum para o Progresso da América do Sul). Proposto pelo presidente chileno, Sebastian Piñera, o Prosul já havia sido anunciado em março de $2019^{22}$. Apresentado como mais "flexível”, este organismo é muito menos ambicioso do que a Unasul em matéria de integração regional, o que vai ao encontro dos interesses do governo de Jair Bolsonaro.

\footnotetext{
${ }^{17}$ Por que bombardeiros russos estão aterrissando na Venezuela. BBC Brasil. Publicado em 12 de dezembro de 2018. Disponível em: https://www.bbc.com/portuguese/internacional-46536262.

${ }^{18}$ Instalação de base dos EUA no Brasil gera críticas entre militares. Estadão conteúdo/ Veja. Publicado em 05 de janeiro de 2019. Disponível em: https://veja.abril.com.br/mundo/instalacao-de-base-militar-dos-eua-no-brasil-gera-criticas-entre-militares/.

${ }^{19}$ Crise na Venezuela opõe ala militar aos bolsonaristas radicais no governo. Reportagem de Igor Gielow. Folha de S. Paulo. Publicado em 21 de fevereiro de 2019. Disponível em: https://www1.folha.uol.com.br/mundo/2019/02/crisena-venezuela-opoe-ala-militar-e-os-bolsonaristas-radicais-no-governo.shtml.

${ }^{20}$ Brasil e mais cinco países suspendem participação na Unasul. Reportagem de Maiana Diniz. Agência Brasil / EBC. Publicado em 22 de abril de 2018. Disponível em: http://agenciabrasil.ebc.com.br/internacional/noticia/201804/brasil-e-mais-cinco-paises-suspendem-participacao-na-unasul.

${ }^{21}$ Governo Bolsonaro concorda com criação de novo bloco regional no lugar da Unasul. Reportagem de Eliane Oliveira. O Globo. Publicado em 15 de janeiro de 2019. Disponível em: https://oglobo.globo.com/mundo/governobolsonaro-concorda-com-criacao-de-novo-bloco-regional-no-lugar-da-unasul-23373942.

${ }^{22}$ Brasil formaliza saída da Unasul para integrar Prosul. Reportagem de Andreia Verdélio. Agência Brasil / EBC. Publicado em 19 de abril de 2019. Disponível em: http://agenciabrasil.ebc.com.br/internacional/noticia/2019-04/brasilformaliza-saida-da-unasul-para-integrar-prosul.
} 
Contudo, a Unasul não foi o único bloco regional preterido por Bolsonaro. Antes de sua posse, o Mecosul também foi alvo de questionamentos pelo presidente eleito e por seus correligionários. Em outubro de 2018, Paulo Guedes, que já havia sido anunciado como ministro da economia do novo governo, chegou a dizer que o Mercosul não seria tratado como uma prioridade pelo governo Bolsonaro ${ }^{23}$.

O novo governo brasileiro, assim como o argentino, defenderam o fim da tarifa externa comum do $\mathrm{Mercosul}^{24}$, o que, na prática, seria um recuo na integração econômica do bloco, pois transformaria a atual união aduaneira em área de livre comércio. Já em janeiro de 2019, o governo Bolsonaro anunciou que excluiria a palavra Mercosul e seu símbolo (a constelação do Cruzeiro do Sul) dos passaportes expedidos no Brasil ${ }^{25}$. Apesar de simbólica, esta decisão revela como o bolsonarismo se incomoda com a integração regional que vai além das relações comerciais.

É importante destacar que o bolsonarismo passou a influenciar a política externa brasileira ainda nos últimos meses do governo Temer $^{26}$. A decisão de Michel Temer de retirar a candidatura brasileira para sediar o COP 25 (vigésima quinta Conferência das Partes da Convenção do Clima das Nações Unidas), que ocorrerá em novembro de 2019, por exemplo, se deveu a um pedido de Bolsonaro $^{27}$. Vale lembrar que parte da cúpula bolsonarista é avessa às discussões sobre as mudanças climáticas globais, preferindo chamar de "climatismo" 28 as iniciativas para debater este problema.

Um discurso marcante de Jair Bolsonaro e de seus correligionários é o de que o seu governo desataria as "amarras ideológicas” da política externa brasileira. Em seu discurso de posse,

\footnotetext{
${ }^{23}$ Paulo Guedes diz que Mercosul não será uma prioridade. Isso é ruim? Reportagem de Gabriela Ruic. Exame. Publicado em 30 de outubro de 2018. Disponível em: https://exame.abril.com.br/mundo/paulo-guedes-diz-que-mercosul-nao-sera-uma-prioridadeisso-e-ruim/.

${ }^{24}$ Bolsonaro e Macri querem rever tarifa externa comum do Mercosul. Reportagem de Ricardo Della Coletta, Talita Fernandes e Gustavo Uribe. Folha de S. Paulo. Publicado em 16 de janeiro de 2019. Disponível em: https://www1.folha.uol.com.br/mundo/2019/01/bolsonaro-e-macri-querem-rever-tarifa-externa-comum-domercosul.shtml.

${ }^{25}$ Governo anuncia que passaporte excluirá inscrição 'Mercosul' e adotará brasão da República. Reportagem de Guilherme Mazui. G1. Publicado em 23 de janeiro de 2019. Disponível em:

https:/g1.globo.com/politica/noticia/2019/01/23/governo-diz-que-brasil-deixara-de-adotar-passaporte-com-simbolo-domercosul.ghtml.

${ }^{26}$ Conforme previsto na Lei $\mathrm{n}^{\mathrm{o}} 10.609$, de 20 de dezembro de 2002, é facultado ao governo eleito instituir um governo de transição para se inteirar do funcionamento dos órgãos e entidades da administração pública federal até a data de sua posse. O governo eleito pode nomear membros para acompanhar algumas atividades do governo que está em vias de encerrar, o que, por óbvio, além de facilitar a programação do novo governo, também pode impactar antecipadamente na organização e na condução das políticas. O governo de transição de Jair Bolsonaro foi instalado formalmente no dia 07 de novembro de 2018 e, naquele momento, foram anunciados 27 nomes que comporiam a equipe de transição.

${ }^{27}$ Bolsonaro diz que pediu cancelamento da COP-25 no Brasil e cita 'Triplo A'. Reportagem de André de Souza, Eduardo Bresciani e Mateus Coutinho. O Globo. Publicado em 28 de novembro de 2018. Disponível em: https://oglobo.globo.com/sociedade/bolsonaro-diz-que-pediu-cancelamento-da-cop-25-no-brasil-cita-triplo-a-23266445. ${ }^{28}$ Novo chanceler diz que esquerda criou "ideologia da mudança climática”. Reportagem de Raphael Di Cunto, Carla Araújo e Carolina Freitas. Valor Econômico. Disponível em: https://www.valor.com.br/politica/5985233/novochanceler-diz-que-esquerda-criou-\%3Fideologia-da-mudanca-climatica.
} 
inclusive, afirmou que iria "retirar o viés ideológico de nossas relações internacionais"29. Na visão do novo presidente e de seus apoiadores, a política externa petista deu muita importância para os compromissos ideológicos, em detrimento dos interesses nacionais. Contudo, ao afirmar que os posicionamentos do novo governo não serão ideológicos, o discurso bolsonarista sugere que somente as posições à esquerda do espectro político poderiam ser consideradas ideológicas.

É importante ressaltar que, de fato, os governos petistas assumiram posições, incluindo nas relações exteriores, com base na doutrina ideológica defendida pelo PT. Aliás, o mesmo foi feito por todos os demais governos brasileiros. No entanto, as administrações petistas também assumiram um enorme pragmatismo político. Algo semelhante também ocorreu no governo Geisel, que não se limitou à ideologia anticomunista ligada à Doutrina de Segurança Nacional e, pragmaticamente, ampliou as relações do Brasil com o mundo. Algumas das principais pautas da política externa da "era petista" extravasaram os compromissos ideológicos do partido. É o caso dos esforços diplomáticos para ampliar as agroexportações e para transformar o Brasil numa "potência agroenergética", algo que beneficiou enormemente um setor - o agronegócio - que, tradicionalmente, se opõe ao PT devido à defesa histórica do partido em favor da reforma agrária. Inclusive, este setor apoiou maciçamente a candidatura de Bolsonaro nas últimas eleições ${ }^{30}$.

Ao desconvidar representantes dos governos da Venezuela, de Cuba e da Nicarágua (todos vistos como de esquerda e aliados do PT) para a cerimônia de posse ${ }^{31}$, o governo tratou ex-aliados como inimigos, criando rusgas diplomáticas desnecessárias. A justificativa utilizada para o desconvite foi a de que estes governos são antidemocráticos e que oprimem seus povos. Contudo, esta decisão contraria o protocolo do Itamaraty, segundo o qual governos sul-americanos usualmente são convidados para a cerimônia de posse presidencial ${ }^{32}$. Apesar de os graves excessos cometidos pelos governos venezuelano e nicaraguense e do histórico ditatorial de Cuba, a justificativa não se sustenta, tendo em vista que outros governos acusados de violações aos direitos humanos não foram vetados para a posse, como são os casos da Arábia Saudita e da Coreia do

\footnotetext{
${ }^{29}$ Discurso do Presidente da República, Jair Bolsonaro, durante cerimônia de Recebimento da Faixa Presidencial-Brasilia, $1^{\circ}$ de janeiro de 2019. Ministério de Relações Exteriores. Disponível em: http://www.itamaraty.gov.br/pt-BR/discursos-artigos-e-entrevistascategoria/presidente-da-republica-federativa-do-brasil-discursos/19899-discurso-do-presidente-da-republica-jair-bolsonaro-durante-cerimonia-derecebimento-da-faixa-presidencial-brasilia-1-de-janeiro-de-2019.

${ }^{30}$ Parlamentares ligados ao agronegócio oficializam apoio a Bolsonaro. Reportagem de Jussara Soares. O Globo. Publicado em 02 de outubro de 2018. Disponível em: https://oglobo.globo.com/brasil/parlamentares-ligados-aoagronegocio-oficializam-apoio-bolsonaro-23119245

${ }^{31}$ Nicarágua é o terceiro país vetado para a posse da posse presidencial. Reportagem de Mariana Haubert. Estadão. Publicado em 23 de dezembro de 2018. Disponível em: https://politica.estadao.com.br/noticias/geral,nicaragua-eterceiro-pais-vetado-da-posse-presidencial,70002656577.

${ }^{32}$ Venezuela contradiz futuro ministro e diz que Brasil convidou Maduro para posse de Bolsonaro. G1. Publicado em 16 de dezembro de 2018. Disponível em: https://g1.globo.com/mundo/noticia/2018/12/16/venezuela-contradizfuturo-ministro-e-diz-que-brasil-convidou-maduro-para-posse-de-bolsonaro.ghtml.
} 
Norte $^{33}$. Curiosamente, dois extremos do espectro político. Enquanto a monarquia absolutista e teocrática da Arábia Saudita poderia ser classificada como de extrema-direita, a ditadura comunista norte-coreana poderia ser considerada de extrema-esquerda. E por que Bolsonaro não restringiu a presença da Coreia do Norte, já que é um regime de extrema-esquerda que coleciona muito mais violações aos direitos humanos do que Venezuela, Cuba e Nicarágua juntos? A resposta talvez esteja na aproximação entre o presidente dos EUA, Donald Trump, e o ditador norte-coreano, Kim Jong-un ${ }^{34}$. De fato, o governo Bolsonaro não apenas se esforça em agradar os EUA, como deseja seguir os seus passos na geopolítica internacional.

A indisposição diplomática com Cuba guarda uma dramaticidade a parte, já que ela provocou, ainda durante o governo de transição, a saída de milhares de médicos cubanos que trabalhavam aqui graças a um convênio - ligado ao programa petista "Mais Médicos". O presidente eleito, em algumas ocasiões, questionou a presença de médicos cubanos no Brasil e propôs uma revalidação dos diplomas destes profissionais, algo não previsto no contrato entre os dois países ${ }^{35}$. Em retaliação, o governo cubano resolveu romper unilateralmente o convênio e convocar o retorno destes profissionais.

Ao anunciar medidas que vão de encontro com diferentes setores da sociedade brasileira, justamente em função de seus compromissos ideológicos, o governo Bolsonaro ampliou o viés ideológico da diplomacia brasileira. Além das indisposições "gratuitas" com Venezuela, Nicarágua e Cuba, a saída do Pacto Mundial de Migração e a possibilidade de transferência da embaixada brasileira de Tel Aviv para Jerusalém também revelam que o viés ideológico está sendo colocado acima dos interesses nacionais.

No dia 08 de janeiro, isto é, apenas oito dias depois da posse, o novo governo informou oficialmente à ONU que o país estava se retirando do Pacto Mundial de Migração ${ }^{36}$. Esta decisão se baseou em discursos com alto viés ideológico, semelhante ao utilizado por alguns governos ultranacionalistas de países europeus. Não é por acaso que lideranças de extrema-direita de países como Itália e Hungria vêm elogiando Jair Bolsonaro ${ }^{37}$. Além disso, esta decisão também reflete a

\footnotetext{
${ }^{33}$ Maduro não foi convidado para posse de Bolsonaro, diz futuro chanceler. O Globo. Publicado em 16 de dezembro de 2018. Disponível em: https://oglobo.globo.com/mundo/maduro-nao-foi-convidado-para-posse-debolsonaro-diz-futuro-chanceler-23309252.

${ }^{34}$ Trump diz que ele e Kim Jong-un estão 'apaixonados'. Reportagem de AFP. G1. Publicado em 30/09/2018. Disponível em: https://g1.globo.com/mundo/noticia/2018/09/30/trump-diz-que-ele-e-kim-jong-un-estaoapaixonados.ghtml.

${ }^{35}$ Cuba decide sair do Mais Médicos após condições anunciadas por Bolsonaro. Reportagem de Beatriz Jucá. EL PAÍS. Publicado em 14 de novembro de 2018. Disponível em: https://brasil.elpais.com/brasi/2018/11/14/politica/1542212032_463199.html.

${ }^{36}$ Bolsonaro retira Brasil de Pacto de Migração e ONU teme reviravolta. Reportagem de Jamil Chade. Estadão. Publicado em 08 de janeiro de 2019. Disponível em: https://internacional.estadao.com.br/noticias/geral,brasil-deixapacto-global-pela-imigracao-da-onu,70002671958.

${ }^{37}$ Premier húngaro Orbán elogia Bolsonaro: 'Mais apta definição de democracia cristã moderna' . O Globo. Publicado em 11 de janeiro de 2019. Disponível em: https://oglobo.globo.com/mundo/premier-hungaro-orban-elogiabolsonaro-mais-apta-definicao-de-democracia-crista-moderna-23363154.
} 
influência que o atual governo estadunidense tem sobre o Brasil. Uma das pautas mais importantes do governo Trump trata, justamente, da questão migratória. Os EUA têm procurado de todas as maneiras restringir ainda mais a sua política imigratória. Apesar de possuir muito mais emigrantes ${ }^{38}$ do que imigrantes ${ }^{39}$ - sendo que grande parte destes emigrantes vivem nos EUA de maneira irregular -, o Brasil assumiu uma posição que defende restrições à migração internacional.

As falas preconceituosas do presidente e de seu e filho, o deputado (e presidente da Comissão de Relações Exteriores e de Defesa Nacional) Eduardo Bolsonaro, em relação aos imigrantes que vivem nos EUA, assim como o apoio dado às políticas anti-imigratórios do governo estadunidense ${ }^{40}$ contrariam, inclusive, os interesses de parte do eleitorado bolsonarista. Vale mencionar que Jair Bolsonaro recebeu, no segundo turno, 81,7\% dos votos dos brasileiros residentes nos $\mathrm{EUA}^{41}$.

Contraditoriamente, mesmo não sendo destino da migração internacional, o governo brasileiro desconsidera uma pauta importante para os países do Sul, que tendem a defender políticas migratórias mais tolerantes. Em suma, além de abandonar o seu papel de liderança do Sul, esta decisão contraria o interesse de muitos brasileiros que vivem ou que querem viver no exterior.

A visita de Bolsonaro aos EUA, em março de 2019, foi um “divisor de águas” na política externa brasileira. Nessa viagem, Bolsonaro "renunciou" ainda mais ao papel exercido pelo Brasil como líder dos países do Sul. Durante a viagem de Bolsonaro, o Brasil abriu mão de seu status de país emergente na OMC em troca do apoio estadunidense para a entrada brasileira na OCDE. Além disso, o Brasil também confirmou uma concessão unilateral de criar uma cota de importação para 750 mil toneladas de trigo estadunidense ${ }^{42}$. Atualmente, a maior parte do trigo importado pelo Brasil vem da Argentina.

\footnotetext{
${ }^{38}$ Segundo o Itamaraty, mais de três milhões de brasileiros viviam fora do Brasil em 2016, sendo que quase metade vivia nos EUA. Para mais informações, ver tabela do ministério de relações exteriores discriminando os destinos dos emigrantes brasileiros disponível em: http://www.brasileirosnomundo.itamaraty.gov.br/a-comunidade/estimativaspopulacionais-das-comunidades/Estimativas\%20RCN\%202015\%20-\%20Atualizado.pdf.

${ }^{39}$ Estimativas dos últimos anos apontavam que aproximadamente 700.000 imigrantes viviam no Brasil, o que representaria apenas $0,3 \%$ de sua população, muito abaixo da média mundial, que é de $1,7 \%$. Para mais informações, ler a entrevista que o professor Wagner Oliveira concedeu ao Nexo Jornal em 17 de março de 2017. Disponível em: https:/www.nexojornal.com.br/entrevista/2017/08/26/Qual-o-retrato-da-migra\%C3\%A7\%C3\%A3o-estrangeira-hojeno-Brasil-segundo-este-especialista.

${ }^{40}$ Bolsonaro diz que maioria de imigrantes não tem boas intenções e que apoia muro de trump. Reportagem de Sarah Mota Resende. Folha de S. Paulo. Publicado em 19 de março de 2019. Disponível em: https://www1.folha.uol.com.br/mundo/2019/03/bolsonaro-diz-que-maioria-de-imigrantes-nao-tem-boas-intencoes-eque-apoia-muro-de-trump.shtml.

${ }^{41}$ Comunidade brasileira nos Estados Unidos votou em Bolsonaro e rejeita Trump, aponta pesquisa inédita. Reportagem de Henrique Gomes Batista. Época. Publicado em 11 de novembro de 2018. Disponível em: https://epoca.globo.com/comunidade-brasileira-nos-estados-unidos-votou-em-bolsonaro-rejeita-trump-aponta-pesquisainedita-23228046.

${ }^{42}$ Nota EUA/Brasil expõe troca de apoio na OCDE por novo status na OMC. Reportagem de Daniel Rittner.Valor econômico. Publicado em 19 de março de 2019. Disponível em: https://www.valor.com.br/brasil/6169153/notaeuabrasil-expoe-troca-de-apoio-na-ocde-por-novo-status-na-omc.
} 
Durante a campanha eleitoral, Bolsonaro prometeu transferir a embaixada brasileira de Tel Aviv para Jerusalém. Contudo, o novo presidente tem sido desencorajado por setores estratégicos, incluindo parte dos militares. Ao transferir a embaixada, o Brasil reconheceria Jerusalém como a capital de Israel e poria fim à histórica posição de neutralidade do Brasil frente à "questão árabeisraelense". Fortemente criticada pela grande maioria dos "países islâmicos", tal transferência teria vários custos. Em primeiro lugar, ela impactaria negativamente as agroexportações brasileiras para os "países islâmicos" - que, aliás, superam em dezenas de vezes as exportações brasileiras para Israel $^{43}$. Em segundo lugar, o Brasil passaria a encontrar dificuldade para negociar maiorias em foros multilaterais (como na OMC e na assembleia geral da ONU, por exemplo), pois não teria o apoio dos "países islâmicos". E, como se não bastasse, o Brasil poderia se tornar alvo de grupos extremistas islâmicos, o que comprometeria a segurança nacional.

Com viés religioso, a transferência da embaixada atenderia a uma demanda de grupos pentecostais e neopentecostais - que, inclusive, apoiaram a candidatura de Bolsonaro durante as eleições. O "sionismo cristão" presente nestas igrejas interpreta a transferência da embaixada brasileira para Jerusalém como um reconhecimento das profecias do velho testamento ${ }^{44}$. Além do viés religioso, a transferência da embaixada também atenderia ao compromisso ideológico do governo Bolsonaro com a "frente conservadora internacional" liderada pelo governo de Donald Trump. Apesar de, até o momento, apenas os EUA e a Guatemala terem transferido suas embaixadas para Jerusalém, outros países governados por políticos e/ou partidos ultraconservadores também têm estreitado seus laços com o governo israelense ${ }^{45}$.

Devido à pressão de parte dos militares que integram o governo e do lobby do agronegócio, o governo brasileiro recuou e resolveu adiar a transferência da embaixada. Porém, como um indicativo do estreitamento de laços com Israel, o governo Bolsonaro resolveu abrir um escritório comercial em Jerusalém ${ }^{46}$, semelhante ao que país mantém em Taiwan ${ }^{47}$. De qualquer forma, desde o governo de transição o Brasil já vinha se posicionado favoravelmente aos interesses israelenses. Em dezembro de 2018, por exemplo, o Brasil rompeu com seu tradicional posicionamento em apoio

\footnotetext{
${ }^{43}$ Embaixada em Jerusalém: o que o Brasil pode ganhar e perder se aproximando de Israel. Reportagem de Nathalia Passarinho. BBC Brasil. Publicado em 11 de janeiro de 2019. Disponível em: https://www.bbc.com/portuguese/brasil-46815018.

${ }^{44}$ Para mais detalhes sobre o interesse de grupos evangélicos na transferência da embaixada brasileira de Tel Aviv para Jerusalém, leia a entrevista que Clemir Fernandes (pastor da igreja batista, sociólogo e professor do ISER) concedeu à Agência Pública em 22 de janeiro de 2019. Disponível em: https://apublica.org/2019/01/os-eleitos/.

${ }^{45}$ Salvini adere à aliança de Netanyahu com o nacionalismo populista europeu. Reportagem de Juan Carlos Sanz. EL PAÍS. Publicado em 12 de dezembro de 2018. Disponível em: https:/brasil.elpais.com/brasil/2018/12/12/internacional/1544575469_485740.html.

${ }^{46}$ Bolsonaro troca embaixada por escritório em Jerusalém, mas não evita retaliação palestina. Reportagem de Juan Carlos Sanz. EL PAÍS. Publicado em 01 de abril de 2019. Disponível em: https://brasil.elpais.com/brasil/2019/03/31/politica/1554060705_325198.html. ${ }^{47}$ Único escritório comercial do Brasil semelhante ao de Jerusalém fica em Taiwan, diz Itamaraty. Reportagem de Fábio Amato. G1. Publicado em 02 de abril de 2019. Disponível em:

https:/g1.globo.com/politica/noticia/2019/04/02/unico-escritorio-comercial-do-brasil-semelhante-ao-de-jerusalem-ficaem-taiwan-diz-itamaraty.ghtml.
} 
aos palestinos e votou contra o Hamas em uma resolução proposta pelos EUA ${ }^{48}$. Já durante o governo Bolsonaro, em março de 2019, o Brasil voltou a contrariar sua tradição diplomática nessa matéria e votou contra duas resoluções críticas às violações cometidas por Israel. Uma tratava das violações de direitos humanos de cidadãos sírios que vivem nas Colinas de Golã (território ocupado por Israel desde 1967) e a outra tratava das violações cometidas na Faixa de Gaza em 2014. Apesar disso, o Brasil votou favoravelmente aos Palestinos em outras duas resoluções e se absteve numa quinta votação. No final, todas as resoluções foram aprovadas, incluindo as que o Brasil foi contrário $^{49}$.

Apesar de não podermos afirmar que haja uma coordenação internacional dos governos ultraconservadores, é inegável que os movimentos de extrema-direita nos diferentes países têm se influenciado. Jair Bolsonaro, desde a campanha presidencial, tem procurado se aproximar destes movimentos $^{50}$. Não por acaso, uma das grandes novidades do novo governo e que contrasta enormemente com todos os que o precederam se refere ao seu posicionamento desconfiado e, muitas vezes, hostil ao multilateralismo. Vale lembrar que as lideranças ultraconservadoras mundiais contestam o multilateralismo. Assim, ao criticar organismos e acordos internacionais, Bolsonaro segue os passos de Donald Trump e adere à "onda conservadora internacional". Ainda durante a campanha eleitoral, em agosto de 2018, Bolsonaro chegou a dizer que se fosse eleito retiraria o Brasil da ONU. Naquela ocasião, o então candidato chegou a afirmar que o organismo "não serve para nada, é um local de reunião de comunistas". Apesar de ter voltado atrás em relação a esta declaração, Bolsonaro prometeu que o país sairia do Conselho de Direitos Humanos da $\mathrm{ONU}^{51}$, seguindo os passos dos EUA, que se retiraram em junho de 2018.

A submissão da nova política externa brasileira aos interesses estadunidenses no que se refere, entre outras coisas, à crise venezuelana, à questão migratória, ao conflito árabe-israelense e ao Conselho de Direitos Humanos da ONU aproximaram sobremaneira o governo Trump do governo Bolsonaro. Na verdade, há décadas o Brasil não era tão próximo aos EUA ${ }^{52}$. E esta aliança deve se aprofundar ainda mais, pelos menos enquanto estes países seguirem sendo governados por

\footnotetext{
${ }^{48}$ Brasil se alinha a EUA e Israel em votação contra Hamas na ONU. Folha de S. Paulo. Publicado em 07 de dezembro de 2019. Disponível em: https://www1.folha.uol.com.br/mundo/2018/12/brasil-se-alinha-a-eua-e-israel-emvotacao-contra-hamas-na-onu.shtml.

${ }^{49}$ Brasil rompe tradição diplomática e vota a favor de Israel na ONU. Folha de S. Paulo. Publicado em 22 de março de 2019. Disponível em: https://www1.folha.uol.com.br/mundo/2019/03/brasil-muda-tradicao-diplomatica-e-vota-afavor-de-israel-na-onu.shtml.

${ }^{50}$ A relação de Bolsonaro com a extrema-direita internacional. Reportagem de João Paulo Charleaux. Nexo Jornal. Publicado em 03 de outubro de 2018. Disponível em: https://www.nexojornal.com.br/expresso/2018/10/03/Arela\%C3\%A7\%C3\%A3o-de-Bolsonaro-com-a-extrema-direita-internacional.

${ }^{51}$ Jair Bolsonaro promete virada na política externa. Reportagem de Patrícia Campos Mello e Luciana Coelho. Folha de S. Paulo. Publicado em 31 de dezembro de 2018. Disponível em: https://www1.folha.uol.com.br/mundo/2018/12/jair-bolsonaro-promete-virada-na-politica-externa.shtml.

${ }^{52}$ Aliança entre Brasil e EUA está 'mais forte do que nunca', diz conselheiro da Casa Branca. Folha de S. Paulo. Publicado em 05 de fevereiro de 2019. Disponível em: https://www1.folha.uol.com.br/mundo/2019/02/alianca-entrebrasil-e-eua-esta-mais-forte-do-que-nunca-diz-conselheiro-da-casa-branca.shtml.
} 
grupos ideologicamente próximos. No entanto, uma mudança no governo estadunidense pode comprometer esta aliança e deixar o Brasil numa situação de isolamento internacional.

\section{CONCLUSÕES}

Mudanças de governo tendem a impactar a política externa de um país, especialmente se o novo governo tiver uma posição ideológica muito diferente do anterior. Na verdade, todo governo imprime sua marca ideológica em diferentes matérias, incluindo na política externa. Contudo, seja por pragmatismo comercial ou para garantir a governabilidade, os princípios ideológicos de um governo pode (e deve) se combinar com as tradições diplomáticas do país e não romper drasticamente com o que foi traçado pelos governos anteriores.

Ao chegar ao poder, o PT inovou em alguns aspectos, mas também manteve os rumos estabelecidos pelos sucessivos governos que vinham dirigindo o país desde a redemocratização. De uma maneira geral, podemos destacar cinco aspectos da política externa lulo-petista, a saber: i) busca por mais protagonismo internacional, especialmente através da tentativa de inserção do Brasil no Conselho de Segurança da ONU; ii) esforço para se estabelecer como uma liderança do Sul; iii) liderança no processo de integração regional da América do Sul; iv) empenho para aprofundar o multilateralismo, através, principalmente, da consolidação dos BRICS e do incremento das relações Sul-Sul; v) manutenção de uma política externa pragmática, apesar do esforço para se aproximar de países latino-americanos governados por grupos ideologicamente próximos do PT.

O impeachment de Dilma Rousseff e, principalmente, a vitória de Jair Bolsonaro, alteraram profundamente a política externa brasileira. Constatamos cinco principais frentes de ação da política externa bolsonarista, a saber: i) alinhamento subserviente aos EUA; ii) distanciamento diplomático de alguns antigos países aliados, todos eles vistos como de esquerda e muito próximos do PT; iii) aproximação de países governados por grupos de direita e extrema-direita; iv) revisão da importância do multilateralismo e da integração regional; v) mudança brusca de posição no que se refere à questão árabe-israelense.

A despeito do que vem sendo discursado desde a campanha eleitoral de 2018, o governo Bolsonaro não está rompendo com as "amarras ideológicas" da política externa brasileira. Muito pelo contrário, pois o que o novo governo está fazendo é “amarrar” outra ideologia ao Itamaraty. O viés ideológico se tornou ainda mais relevante para a tomada de decisões. Assim, contradizendo com o que vinha ocorrendo nas últimas três décadas, as decisões tomadas pelo novo governo estão rompendo com o tradicional pragmatismo da política externa brasileira.

Todavia, algumas novidades da política externa brasileira têm encontrado resistência de setores extremamente influentes. A forma como o governo vem tratando a crise venezuelana e a 
“questão árabe-israelense", por comprometerem a segurança nacional, vêm incomodando os militares que compõem o governo, além de parte das forças armadas. Neste sentido, os rumos da nova política externa brasileira também vão depender da maneira como os círculos militares reagirão às iniciativas do presidente e de seu chanceler.

As decisões anunciadas por Bolsonaro e por seu chanceler nos permitem dizer que, de maneira geral, o Brasil desistiu da posição anteriormente conquistada como líder dos países do Sul. Além disso, parece pouco provável que o Brasil se empenhe como antes para a consolidação da integração regional sul-americana. Enfim, é de se esperar que o país recue ainda mais em matéria de multilateralismo, o que tende a afetar seriamente a Ordem Internacional.

A ascensão de movimentos ultranacionalistas e de extrema-direita está alterando bruscamente a geopolítica mundial. Devido ao peso (geo)político, demográfico e econômico do Brasil, a "guinada à direita" experimentada por este país tende a promover ainda mais esta "onda conservadora". É dever dos intelectuais acompanhar criticamente as mudanças que estão em curso, seja para denunciar os retrocessos resultantes destas mudanças ou para propor, quando possível, alternativas.

\section{REFERÊNCIAS}

ALBUQUERQUE, E. S. O lugar do Brasil no cenário geopolítico mundial contemporâneo. Revista da ANPEGE, v. 7, n. 1, p. 229-236, 2011.

ALMEIDA, P. R. Uma política externa engajada: a diplomacia do governo Lula. Revista Brasileira de Política Internacional, v. 47, n. 1, p. 162-184, 2004.

BARROS, M. J. B.; STEINBERGER, M. Uma nova geopolítica dos recursos agroenergéticos? In: CONGRESSO BRASILEIRO DE GEOGRAFIA POLÍTICA, GEOPOLÍTICA E GESTÃO DO TERRITÓRIO. 1., 2014, Rio de Janeiro. Anais... Porto Alegre: Letral, 2014. p. 415-425.

BECKER, B.; EGLER, C. Brasil: uma nova potência regional na Economia Mundo. 6. ed. Rio de Janeiro: Bertrand Brasil, 2010. 267p.

BOBBIO, N. Direita e esquerda - razões e significados de uma distinção política. 3. ed. São Paulo: Editora Unesp, 2011. 129p.

BRANDÃO, C. A. Espaços estatais dos processos de neoliberalização e as recentes reestruturações regulatórias na Escala Nacional do Brasil. In: SUERTEGARAY, D. M. A.; PIRES, C. L. Z.; SILVA, C. A.; PAULA, C. Q. (Orgs.). Geografia e Conjuntura Brasileira, 2017. p. 35-59.

CARVALHO, A. M. P.; GUERRA, E. C. Brasil no século XXI na geopolítica da crise: para onde apontam as utopias? Revista de Política Pública, v. 20, Número Especial, p. 267-280, 2016.

COSTA, W. M. O Brasil e a América do Sul: cenários geopolíticos e os desafios da integração, Confins, n. 7, p. 1-27, 2009. 
COSTA, Wanderley Messias da. THÉRY, Hervé. Oitenta anos de geopolítica no Brasil: da geografia militar a um pensamento estratégico nacional. Revista Tamoios, v. 12, n. 2, p. 4-21, 2016.

PENNA FILHO, P. O Itamaraty nos anos de chumbo - o Centro de Informações do Exterior (CIEX) e a repressão no Cone Sul (1966-1979). Revista Brasileira de Política Internacional, Brasília, v. 52, n. 2, p. 43-62, 2009.

PEREIRA, J. E. A. Geopolítica, Segurança Jurídica e Inserção do Brasil na Questão Energética Internacional. Revista da Escola Superior de Guerra, v. 25, n. 51, p. 49-58, 2010.

ZIBECHI, R. Brasil Potência. Entre a Integração Regional e Um Novo Imperialismo. 1. ed. Rio de Janeiro: Consequência, 2012. 347p.

Trabalho recebido em 12/07/2019 Trabalho aceito em 13/07/2019 